\title{
Oil Extraction from "Morelos Rice” Bran: Kinetics and Raw Oil Stability
}

\author{
J. Zúñiga-Diaz, ${ }^{1,2}$ E. Reyes-Dorantes, ${ }^{1,2}$ A. Quinto-Hernandez, ${ }^{1}$ J. Porcayo-Calderon, ${ }^{2,3}$ \\ J. G. Gonzalez-Rodriguez, ${ }^{3}$ and L. Martinez-Gomez ${ }^{2,4}$ \\ ${ }^{1}$ Tecnológico Nacional de México, Instituto Tecnológico de Zacatepec, Calzada Instituto Tecnológico 27, \\ 62780 Zacatepec, MOR, Mexico \\ ${ }_{2}^{2}$ Instituto de Ciencias Físicas, Universidad Nacional Autónoma de México, Avenida Universidad s/n, 62210 Cuernavaca, MOR, Mexico \\ ${ }^{3}$ CIICAp, Universidad Autónoma del Estado de Morelos, Avenida Universidad 1001, 62209 Cuernavaca, MOR, Mexico \\ ${ }^{4}$ Corrosion y Protección (CyP), Buffon 46, 11590 México City, Mexico
}

Correspondence should be addressed to J. Porcayo-Calderon; jporcayoc@gmail.com

Received 6 March 2017; Revised 2 May 2017; Accepted 9 May 2017; Published 31 May 2017

Academic Editor: Tingyue Gu

Copyright (C) 2017 J. Zúñiga-Diaz et al. This is an open access article distributed under the Creative Commons Attribution License, which permits unrestricted use, distribution, and reproduction in any medium, provided the original work is properly cited.

\begin{abstract}
"Morelos rice" is a variety of rice with certificate of denomination of origin. It is a large grain of opaque appearance and extra large size that is grown exclusively in Morelos state (Mexico). Thus, the quality and characteristics of its rice bran may affect the kinetic of the extraction process of its oil as well as its stability. Therefore, this work is oriented to determine the extraction kinetics of its oil and its oxidative stability. The latter one is obtained through the proposal of a method based on open-circuit potential measurements. The results showed that the rice bran has $21.44 \%$ of raw oil, with a chemical composition (based on fatty acids) of $48.48 \%$ oleic acid, $35.26 \%$ linoleic acid, and $14.54 \%$ palmitic acid, as well as a free fatty acid content of $8.15 \%$. A high percentage of its oil content can be recovered in a short time at room temperature, and its extraction kinetics is a function of both the washing and the diffusion of its oil. Under storage conditions the raw oil has a high stability, at least 8 months, and its oxidative stability was of 24,9 , and 7 hours at $50^{\circ} \mathrm{C}, 80^{\circ} \mathrm{C}$, and $110^{\circ} \mathrm{C}$, respectively.
\end{abstract}

\section{Introduction}

Rice is the second most consumed cereal and is a primary food for over $40 \%$ of the world's population, with Asian countries (China, India, Indonesia, Bangladesh, and Vietnam) leading the world rice production [1]. The rice kernel contains only a small amount of oil (2-3\%), and this is found in the outer layers of the grain. From the processing of the paddy rice, $70 \%$ of endosperm (white rice) is obtained as the main product, and the rest are by-products (20\% shell, $8 \%$ bran, and $2 \%$ germ) [2]. Generally the by-products are destined for animal feed; however, these could serve as raw material for production of oil and other products (pharmaceuticals, antioxidants, biofuels, etc.) [3].

Due to its chemical composition, rice bran is a unique raw material because of its high protein content and fiber, in addition to its oil content and natural antioxidant compounds [4-6]. Its applications in the food industry have high potential because it can increase the nutritional quality of processed foods [2]. However, only a small portion of the total production of rice bran is used for edible oil production [1]. This occurs as a consequence of cell disruption with release of lipase enzymes and various other antinutritional factors (trypsin inhibitors, hemagglutinin-lectin, and phytates), when the bran layers are removed from the endosperm. The contact between such enzymes and oil causes its hydrolysis and the release of free fatty acids and glycerol, thus causing a drastic reduction of its quality and shelf life $[1,2,5,7,8]$. The degradation level of its oil can be so high that its usefulness for human or animal consumption is unsuitable, so its final destination can be as fuel for boilers [1].

However, rice bran could be an excellent candidate for the development of other higher added value products, in particular its oil. Nonedible rice bran oil has been used in products such as cosmetics, paints, soaps, and detergents; 
however, its usefulness for the production of biofuels and other products of industrial interest is important. The use of vegetable oils that do not affect the food chain should be taken into account for the sustainable development of industrial processes. Also, due to its high production, rice bran can be a sustainable source for the synthesis of new bioproducts, without replacement of crops, nor the use of new cropping areas. All this would have repercussions in obtaining new products with low carbon footprint. However, since vegetable oils have differences in both the type of fatty acids and their degree of unsaturations, as well as in their nonsaponifiable constituents, this can impose conditions on their final use for the development of new products [9]. In many countries rice bran has not been used properly, although it is a renewable source of oil.

However, the quality and characteristics of rice bran usually depend on each country, and even in each region, because of the different rice varieties available, as well as the different crop practices and milling of the paddy rice. Therefore, in this paper, the study of the oil extraction kinetics of the "Morelos rice" bran is carried out. The "Morelos rice" has an origin denomination certificate and is considered as one of the best qualities of rice at international level [10]. Besides the kinetic study, the stability of the raw oil under storage conditions for a period of 8 months has been evaluated, and a new method for determining the oil oxidative stability is proposed.

\section{Experimental Procedure}

The rice bran used in this work was collected a few hours after its production from a local mill (Puente de Ixtla, Morelos, Mexico) and dried at $70^{\circ} \mathrm{C}$ until complete elimination of its moisture content before any experimental test.

The oil content was determined by the Soxhlet method according to the procedure suggested in literature [7]. The physicochemical characterization of the extracted oil (density, acid index, iodine index, peroxide index, and saponification index) was performed according to AOAC methods 920.21, 940.28, 920.158, 965.33, and 920.160, respectively. Gas chromatography and FTIR analyzes were also performed.

Prior to the study of the kinetics of oil extraction, the optimal solvent-rice bran ratio $(\mathrm{ml} / \mathrm{g})$ was determined. This was done in a batch-shaken system $(215 \mathrm{rpm})$ at 20 and 40 and $60^{\circ} \mathrm{C}$ for 24 hours, with solvent to rice bran of $4: 1,7: 1,10: 1$, $13: 1,16: 1$, and $19: 1$.

The particle size distribution of the rice bran in its nondefatted and defatted condition was carried out using sieve analysis in accordance with ASTM D 422/63.

The oil extraction kinetics was determined in a similar fashion to that reported in the literature [11]. This was performed as a function of temperature $\left(20,40\right.$, and $\left.60^{\circ} \mathrm{C}\right)$ and extraction time, using the optimum solvent to rice bran ratio previously determined. Because hexane is the solvent most used for the oil extraction from oilseeds, as well as its high extraction efficiency, in this study this solvent was used for all extractions.

Oil stability was determined considering storage conditions (ambient temperature and sunlight absence) for 8
TABLE 1: Physicochemical parameters of the raw oil.

\begin{tabular}{lc}
\hline Density & $0.913 \mathrm{~g} / \mathrm{cm}^{3}$ \\
Saponification index & $182.3 \mathrm{mg} \mathrm{KOH} / \mathrm{g}$ \\
Acidity index & $15.97 \mathrm{mg} \mathrm{KOH} / \mathrm{g}$ \\
Iodine index & $91.38 \mathrm{~g} \mathrm{I}_{2} / 100 \mathrm{~g}$ \\
Peroxide index & $1.4 \mathrm{meq} \mathrm{O}_{2} / \mathrm{kg}$ \\
\hline
\end{tabular}

months, through monitoring the evolution of its physicochemical parameters.

Oxidative stability of the raw oil was determined in accelerated oxidation conditions similar to those used in the so-called Rancimat test. However, in this case, the thermodynamic equilibrium between an inert metal electrode and the deionized water was measured as a function of time. This was determined by measuring the open-circuit potential (OCP) of a gold working electrode (WE) relative to a reference electrode (saturated calomel electrode, SCE) using an ACM Instruments zero-resistance ammeter (ZRA) potentiometer coupled to a personal computer.

\section{Results and Discussion}

3.1. Chemical and Physicochemical Characterization. The moisture content of the rice bran was $6.77 \%$, and its raw oil content was $21.44 \%$. The oil content of the rice bran can vary from 10 to $23 \%$ [2], and the oil content determined is consistent with that reported in other studies $[3,12,13]$. Table 1 reports the physicochemical characteristics of the raw oil.

The oil density also agrees with typical values already reported [14]. As a general rule, such values are affected by the length of the hydrocarbon chains and the presence of unsaturations. Saponification index is related to the average molecular weight of the oil and was estimated at $923.36 \mathrm{~g} / \mathrm{gmol}$, comparable to the average molecular weight of vegetable oils $[15,16]$. Notwithstanding rice bran was collected a few hours after the milling process of the rice grain, the acidity index value of the raw oil was too high. This is a typical condition of the free fatty acid (FFA) concentration obtained during the hydrolysis of the triglycerides by the action of the enzyme lipase [17]. Allowable limits of FFA in the rice bran oil are $10 \%$ and and $5 \%$ for the rice bran when considered for human consumption [4]. Surprisingly, in this study the FFA content was estimated at $8.15 \%$, an interesting result considering that the rice bran was collected few hours after the milling process. As such, this degradation level limits rice bran for food purposes but also offers possible applications in the synthesis of chemical products, as biodiesel and corrosion inhibitors [18-24]. The iodine index is associated with the degree of unsaturations in the oil and indicates the capacity of being oxidized because of the unsaturations present in its hydrocarbon chains. Our determined value is in nice agreement with previous studies [4]. This parameter is important in the synthesis of biofuels because high values of this index suggest a low stability in these materials [25]. Also, considering that the iodine index of the source oil is inherited 


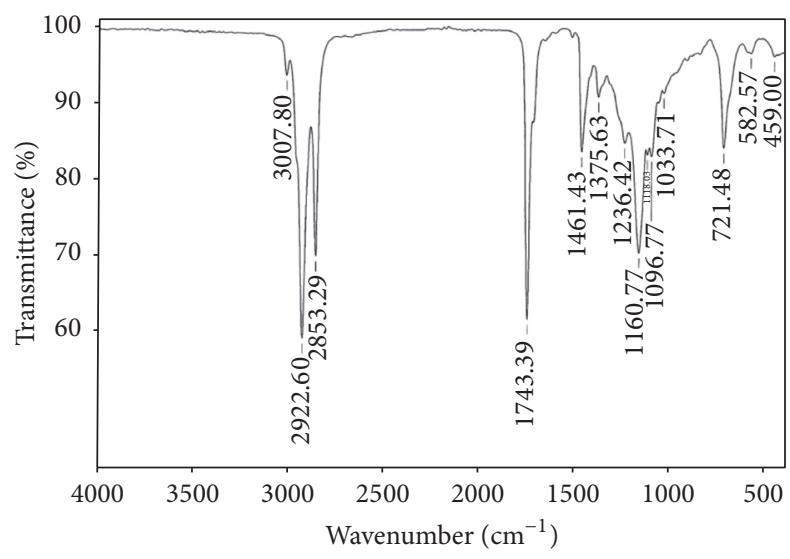

FIGURE 1: FTIR spectrum of the raw oil from rice bran.

to the synthesized biofuel, this parameter is important for extrapolating the possible stability of biofuel. As a result, our estimated value can be considered normal taking into account the fact that the maximum allowable value is 120 for biodiesel, according to the standard EN 14214. Finally, the peroxide index measures the deterioration of alkyl chains in triglycerides, inducing a disagreeable appearance and rancid oil odors. Our value for peroxide index is lower than others reported for crude vegetable oils [26].

Vegetable oils are mixtures of triglycerides which are often composed of different fatty acids. Its physical and chemical properties are related to the chemical structure of the fatty acids bound to glycerol molecule, the saturation degree of the fatty acids, and the length of its hydrocarbon chain. Knowledge of the chemical composition of fatty acids present is important since this often determines its end use. Gas chromatography analysis of the raw oil suggested that the main fatty acids present are palmitic (C16:0), oleic (C18:1), and linoleic acid (C18:2) in proportions of 14.54, 48.48, and $35.26 \%$ by weight, respectively. Fatty acids composition is similar to that reported in the literature for the same type of oil $[2,3,12,18,27]$.

Figure 1 shows the FTIR spectrum of the raw oil. The presence of a shoulder at about $3007 \mathrm{~cm}^{-1}$ is attributed to the stretching vibration of the cis-olefin double bonds $(=\mathrm{C}-\mathrm{H})$. In $2922 \mathrm{~cm}^{-1}$, the asymmetric methylene stretching band appears, as well as the symmetrical methylene stretching band at $2853 \mathrm{~cm}^{-1}$. We also observe vibrational stretching bands for $\mathrm{CH}_{3}$ (at $2853 \mathrm{~cm}^{-1}$ ), the $\mathrm{C}=\mathrm{O}$ group of triglycerides $\left(1743 \mathrm{~cm}^{-1}\right)$, the $\mathrm{CH}_{2}$ group $\left(1461 \mathrm{~cm}^{-1}\right)$, and the stretching corresponding to $-\mathrm{C}-\mathrm{O}-\mathrm{O}\left(\right.$ at $\left.1160 \mathrm{~cm}^{-1}\right)$. Finally, at $721 \mathrm{~cm}^{-1}$, a band is observed due to the overlapping of the methylene balancing vibration and the flexing vibration out of the plane of the cis-disubstituted olefins $(-\mathrm{HC}=\mathrm{CH}-)[28,29]$.

3.2. Oil Extraction Kinetics. Prior to the study of the oil extraction kinetics, the optimal solvent to solid ratio to be used was determined. Figure 2 shows the results obtained at different volume-mass ratios of solvent and rice bran, respectively. The results showed that at a $10-1$ ratio it is
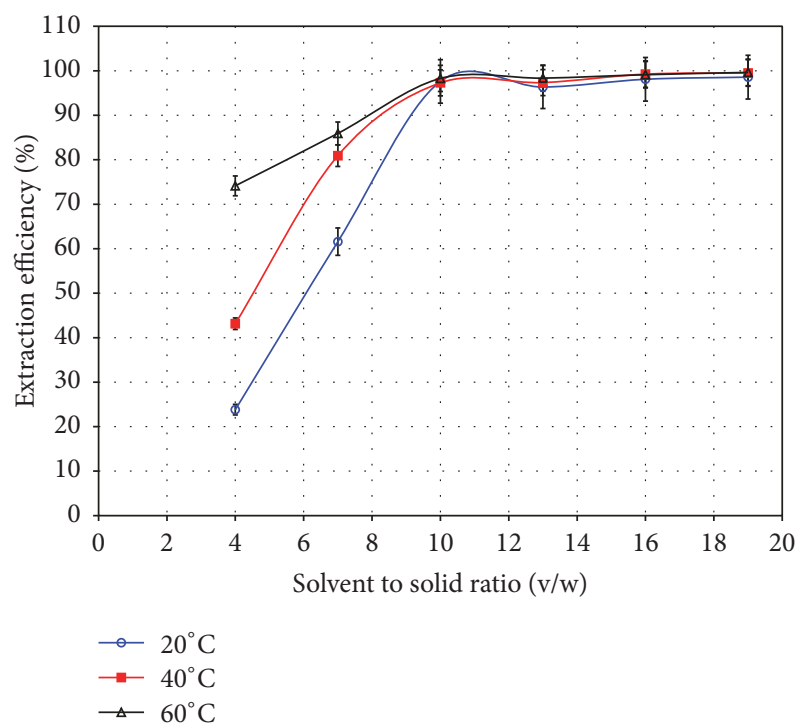

FIGURE 2: Extraction efficiency as a function of the solvent to solid ratio after 24 hours at different temperatures.

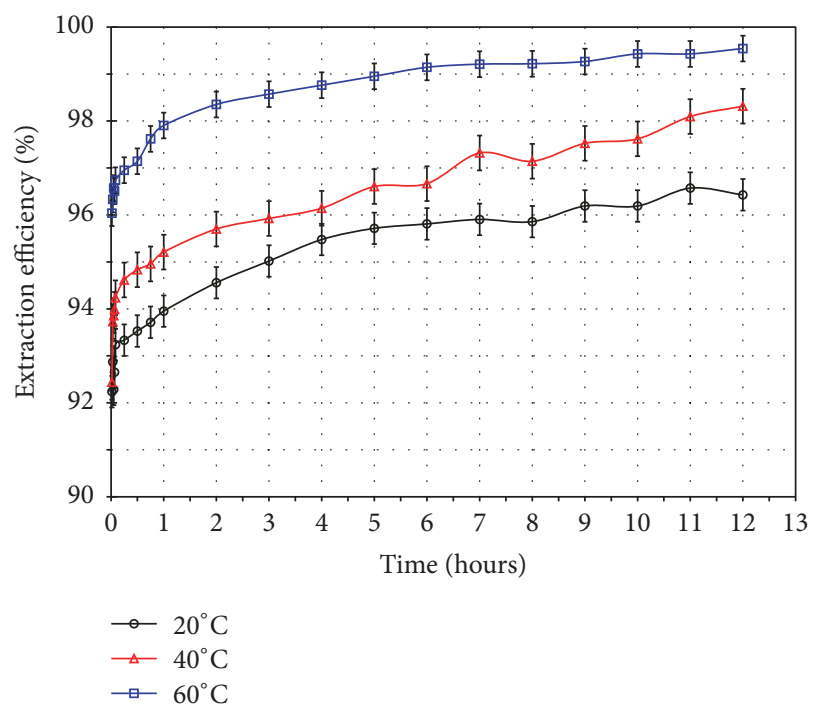

FIGURE 3: Extraction kinetics of the raw oil according to the temperature and extraction time.

possible to extract almost $99 \%$ of the raw oil; using higher ratios shows no a significant contribution to the extraction yields. On the contrary, the use of higher relationships would increase the cost of the extraction process. Based on this information, the oil extraction kinetics was evaluated at different temperatures.

Figure 3 shows the extraction kinetics of the raw oil at 20, 40 , and $60^{\circ} \mathrm{C}$. It is evident that, regardless of the extraction temperature, more than $90 \%$ of the oil was extracted in times less than 15 minutes, and at higher times the average extraction efficiency was greater than 96, 97, and 99\%, respectively. These results suggest that during the milling process the rice bran particles have undergo a great cellular damage or the thickness of the particles is too small. In both 


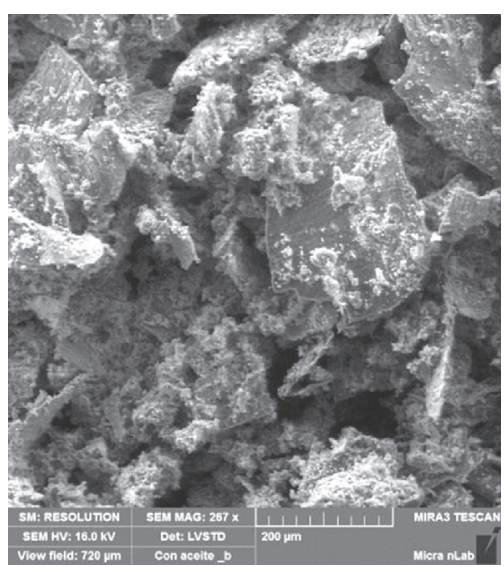

(a)

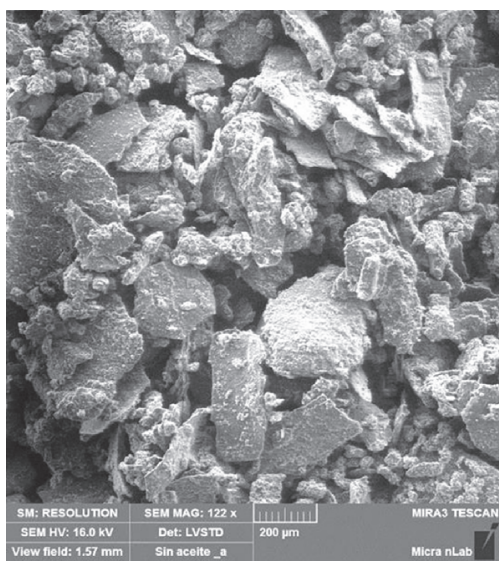

(d)

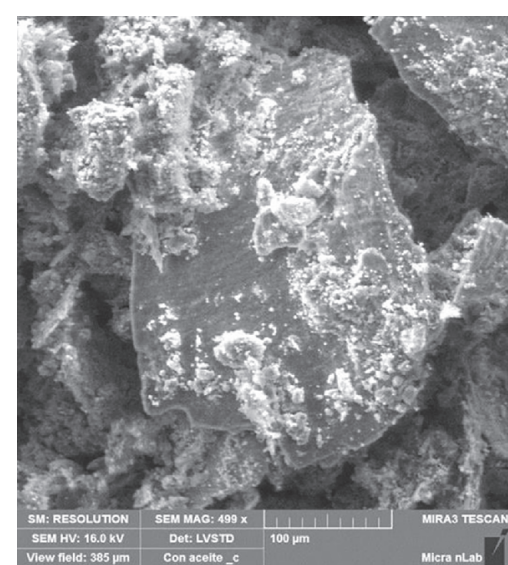

(b)

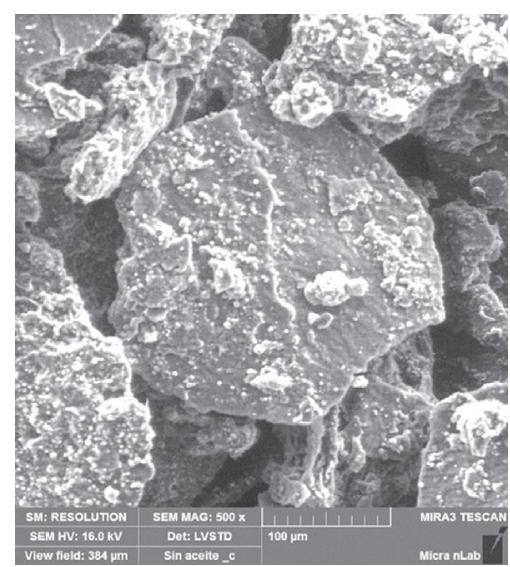

(e)

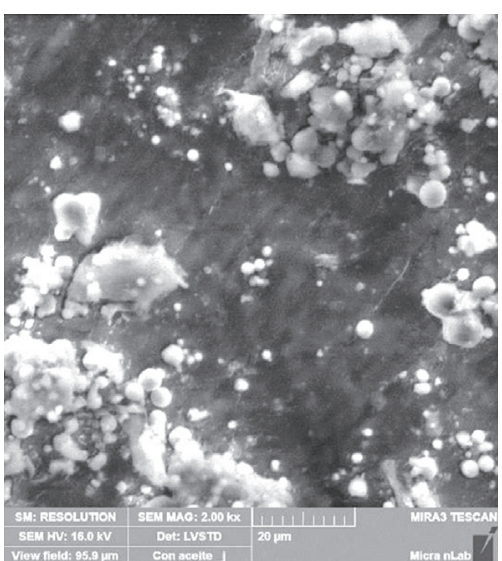

(c)

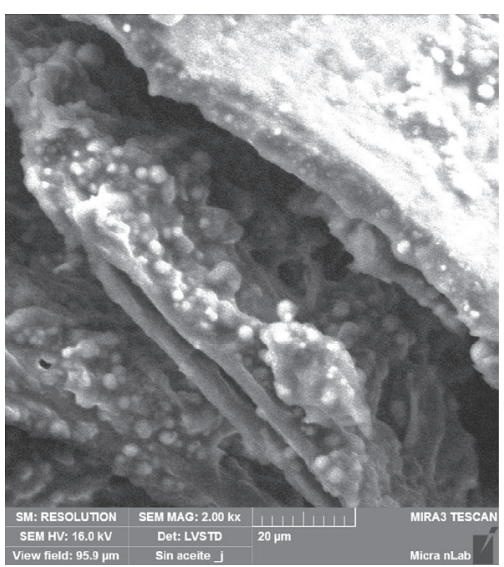

(f)

FIGURE 4: Morphological aspects of the rice bran particles: (a)-(c) nondefatted and (d)-(f) defatted.

considerations, it appears that only a small amount of oil remained occluded into rice bran particles. Therefore, it is inferred that the extraction process was carried out in two stages, where the first one corresponds to the washing of the oil present onto the rice bran particles surface, and the second one to the diffusion of the oil occluded into the rice bran particles.

To understand the high extraction efficiency in short time, the rice bran particles were analyzed through scanning electron microscopy. Figure 4 shows the morphological appearance of the rice bran particles before and after the oil extraction process. The analysis indicated that the nondefatted rice bran (Figures 4(a)-4(d)) consists of flake-like particles with an appreciable amount of fine particles (sizes up to 1 micron) adhered to its surface. The amount of these particles decreases after the oil extraction process (Figures $4(\mathrm{~d})-4(\mathrm{f})$ ), suggesting that its presence onto surface is due to the fact that the oil acts as a binder. Note that the flakes' thickness ranges from 2 to 6 microns (Figure 4(f)) and their maximum average dimensions are $200 * 500 * 6$ microns. This geometry provides a wide contact area and justifies the high extraction efficiency in short times. On the other hand, this high availability of oil makes it susceptible to the action of the enzyme lipase and consequently the high acidity index of the oil as previously discussed.

Figure 5 shows the particle size distribution of the rice bran before and after the oil extraction process. In a nondefatted condition, more than $93 \%$ of the particles in the rice bran have an average size $\geq 125$ microns. Previous studies report that almost $100 \%$ of the particles have an average size $\geq 125$ microns [30]. However, in its defatted condition a redistribution of the fractions was observed, as well as a $30 \%$ decrease in particle content with average size $\geq 125$ microns. At the light of these results, it is suggested that the presence of the oil onto flakes surface favored the formation of aggregates which were disintegrated during the oil extraction, and subsequently the presence of fine particles was significantly increased. This proves the wide contact surface area of the flakes which, along its small thickness, favored the high extraction efficiency.

Mass transfer from a solid phase to a liquid one is dominated by internal resistance. As such, the Fick's second 


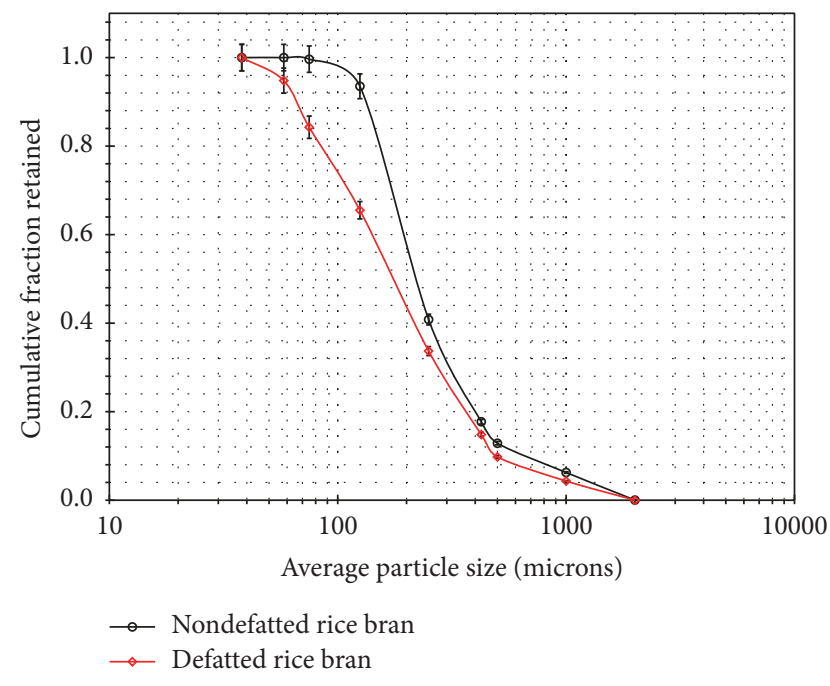

FIGURE 5: Distribution of the average particle size of the rice bran: nondefatted and defatted.

law for diffusion in unstable state is considered as its most accurate representation. The simplest form of this law for unidirectional diffusion of a solute in solid foods is [31]

$$
\frac{\partial c}{\partial t}=\frac{1}{x^{\nu-1}} \frac{\partial}{\partial x}\left(x^{\nu-1} D_{\mathrm{ef}} \frac{\partial c}{\partial x}\right)
$$

where $v=1,2$, and 3, which corresponds to a plate, cylinder, and sphere; respectively, $D_{\text {ef }}$ is the effective diffusion coefficient (also known as apparent diffusion coefficient), which describes the diffusional mass transfer in heterogeneous systems and structurally complex. The relationship is valid assuming an isotropic medium whose structure and diffusion properties are the same in all directions. In the case of materials with flat plate geometry and infinite length it is assumed that the mass transfer occurs mainly in the perpendicular direction to the faces (unidirectional diffusion). Considering the above, the equation is reduced to

$$
\frac{\partial c}{\partial t}=D_{\mathrm{ef}} \frac{\partial^{2} c}{\partial x^{2}}
$$

For the case of a system with unlimited volume, perfectly stirred, and with an initial solute concentration in the solvent equal to zero, the general solution reported is [31]

$$
O_{R}=\frac{q}{q_{0}}=\frac{8}{\pi^{2}} \sum_{n=0}^{n=\infty} \frac{1}{(2 n+1)^{2}} e^{-(2 n+1)^{2} \pi^{2}\left(D_{\mathrm{ef}} t / 2 L^{2}\right)},
$$

where $O_{R}$ is the oil ratio and represents the unaccomplished oil change, $q$ is the amount of oil per unit weight of the solid at $t$ seconds after the diffusion has started, $q_{0}$ is the initial amount of oil into the solid at $t=t_{0}, 2 L$ is the plate thickness, and $D_{\text {ef }}$ is the effective diffusion constant in $\mathrm{m}^{2} \mathrm{~s}^{-1}$. For long times the series converges, and therefore few terms are sufficient for most practical calculations, and all the terms

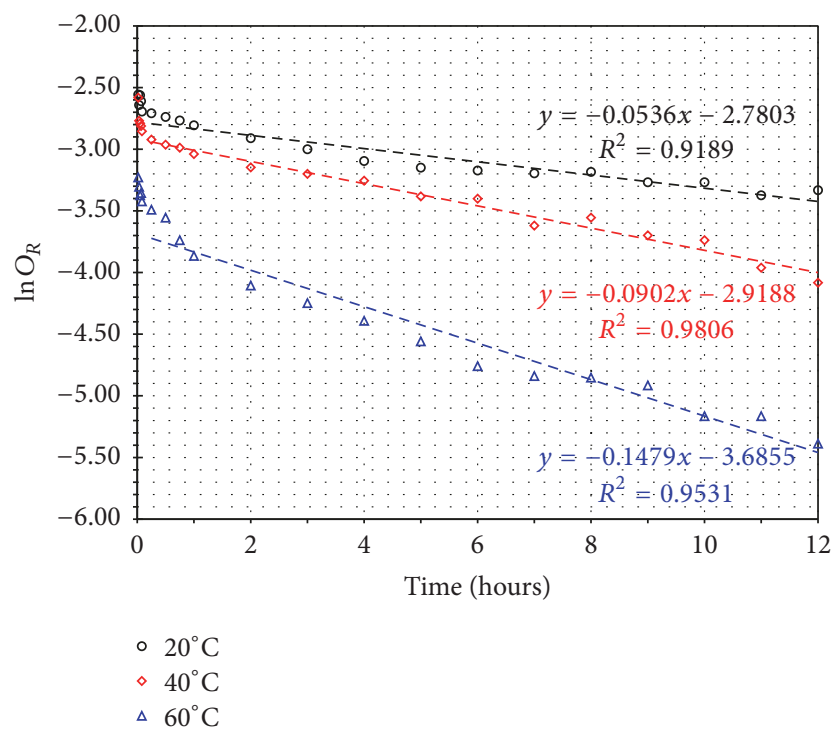

FIGURE 6: Variation of residual oil content as a function of extraction time and temperature (lines: fit to model; points: experimental data).

TABle 2: Diffusion coefficients calculated for the test temperatures.

\begin{tabular}{ll}
\hline Temperature & $D_{\text {ef }}\left(\mathrm{m}^{2} \mathrm{~s}^{-1}\right)$ \\
\hline $20^{\circ} \mathrm{C}$ & $8.69 \times 10^{-14}$ \\
$40^{\circ} \mathrm{C}$ & $1.46 \times 10^{-13}$ \\
$60^{\circ} \mathrm{C}$ & $2.40 \times 10^{-13}$ \\
\hline
\end{tabular}

of the series are negligible, except the first one [31]. Thus, the equation is reduced to

$$
O_{R}=\frac{q}{q_{0}}=\frac{8}{\pi^{2}} e^{-\pi^{2}\left(D_{\mathrm{ef}} t /(2 L)^{2}\right)} .
$$

The equation can be linearized after applying a logarithm and plotted as a function of time $t$. The slope of this line can be used to evaluate the diffusion constant, $D_{\text {ef }}$ :

$$
\ln O_{R}=\ln \frac{q}{q_{0}}=-0.210023-9.86965 \frac{D_{\mathrm{ef}} t}{(2 L)^{2}} .
$$

Figure 6 shows the experimental data according to the previous equation. From the figure it is observed that in short extraction times the series do not converge. This is because a large number of terms are required to obtain the solution; namely, in short times, the extraction process can be controlled by the washing step. Therefore, the fit lines shown in Figure 6 only consider the experimental data obtained at times greater than 5 minutes [31].

The effective diffusion coefficient was determined from the slope of the regression lines using the expression:

$$
D_{\text {ef }}=-\frac{(2 L)^{2} * \text { slope }}{9.86965},
$$

where $2 L=4 * 10^{-6}$ meters, assuming that the average thickness observed by electron microscopy is valid. Table 2 shows the calculated values assuming no external resistance 
TABLE 3: Evolution of the physicochemical parameters of raw oil under storage conditions.

\begin{tabular}{lcccccccccc}
\hline Month & 1 & 2 & 3 & 4 & 5 & 6 & 7 & 8 & $\begin{array}{c}\text { Average value } \\
\text { deviation }\end{array}$ \\
\hline $\begin{array}{l}\text { Density } \\
\text { Saponification }\end{array}$ & 0.912 & 0.915 & 0.916 & 0.919 & 0.918 & 0.918 & 0.917 & 0.916 & 0.916 & 0.002 \\
index & 185.8 & 185.3 & 188.5 & 191.2 & 185.0 & 180.9 & 180.3 & 180.8 & 184.4 & 3.7 \\
Acidity index & 16.4 & 16.9 & 16.4 & 16.8 & 16.5 & 15.4 & 15.2 & 15.1 & 16.1 & 87.1 \\
Iodine index & 91.9 & 88.8 & 84.7 & 88.7 & 88.1 & 83.3 & 83.6 & 83.9 & 3.3 \\
Peroxide index & 1.25 & 1.19 & 1.13 & 1.61 & 2.35 & 3.34 & 4.61 & 5.97 & 2.51 & 1.7 \\
FFA & 8.3 & 8.5 & 8.3 & 8.4 & 8.3 & 7.7 & 7.7 & 7.6 & 8.0 & 0.3 \\
\hline
\end{tabular}

to mass transport and when the internal transport is due exclusively to diffusion processes.

It can be seen that the value of the diffusion coefficients increases with the extraction temperature and that these are around the same magnitude order. An increase in the effective diffusivity is attributed to a decrease of the viscous resistance to the diffusion and simultaneously to a decrease in the solvent viscosity and the increase of the thermal energy of the solute molecules. However, one may expect that by increasing the temperature these values would increase by at least an order of magnitude, as reported before [11, 31]. In addition, the diffusivity values for oils that have been reported in the literature are in the order of $10^{-8}$ to $10^{-11} \mathrm{~m}^{2} / \mathrm{s}[11,31,32]$. It has been reported that when particles exhibit complete rupture of the cell wall leaving a layer of cytoplasm exposed directly to the solvent, high diffusion rates are obtained, but when the cells remain intact the diffusion rate is low [33]. Since the leaching process only occurs when the solid has absorbed the solvent to dissolve the internal solute, one may assume that the cellular structure of the rice bran flakes remained intact and the diffusion rate was strongly affected, as a consequence. However, considering unidirectional diffusion and a flat geometry of the flakes, the oil extraction process with hexane was perfectly adjusted to the nonstationary diffusion model defined by Fick's second law. The effective diffusion coefficient for the internal mass transfer was affected by the structure of the solid because the cell structure of the rice bran flakes remained intact. The effective diffusion coefficient is higher for solids that have been subjected to pretreatment processes, thus inducing degraded cellular structures and increasing the solvent permeability and the mobility of the oil molecules towards the solution [8].

The diffusivity is a function of temperature, pressure, and concentration. Frequently, the relationship between effective diffusivity and absolute temperature follows a first-order process described by the Arrhenius relation:

$$
D_{\mathrm{ef}}=A e^{-E_{a} / R T}
$$

where $E_{a}\left(\mathrm{~J} \mathrm{~mol}^{-1}\right)$ is the activation energy, $R$ is the gas constant $(8.314472 \mathrm{~J} / \mathrm{K}-\mathrm{mol})$, and $A$ is the preexponential factor. The activation energy of the diffusive process can be determined by linearizing the expression and the slope of the line allows its calculation. Once the calculations were performed, an activation energy value of $20.86 \mathrm{~kJ} / \mathrm{mol}$ was obtained. This value has a similar order of magnitude for mass transfer processes affected by diffusion, as suggested previously [31, 34-36].

The above analysis allows confirming that the extraction process of the raw oil was carried out through two main mechanisms, washing and diffusion. The former was the dominant process onto the surface of flakes representing over $92 \%$ of the recoverable oil, while the latter (the diffusion of the occluded oil) represents less than $8 \%$ of the recoverable oil. The latter is a function of the cellular integrity of the rice bran flakes since the effective diffusion coefficients are very low. On the other hand, it is evident that, due to the particular characteristics of "Morelos rice" bran (very thin flakes), it is not necessary to use extraction temperatures higher than room temperature, nor very large extraction times in order to recover the greatest amount of oil. In addition, using higher extraction temperatures increases the costs of the extraction process, and the quality of the extracted oil is affected. At higher temperatures, the oil degradation is accelerated, and the amount of both waxes and free fatty acids is increased.

3.3. Stability of the Raw Oil. The evolution of the physicochemical parameters of the raw oil is shown in Table 3. Raw oil was aged considering storage conditions, that is, at room temperature and in the absence of sunlight, for a period of 8 months. Degradation of edible oils occurs mainly due to a lipid peroxidation process promoted by a freeradical-mediated chain reaction, which can cause alterations in their organoleptic and technological properties that reduce their shelf life $[9,37]$. Differences in chemical composition of vegetable oils influence their stability, sensitivity, and technical qualities. In particular, these properties depend on the degree of unsaturation of the fatty acids, as well as the quantity and quality of the compounds present in the nonsaponifiable fraction [9].

Results in Table 3 suggest that all the physicochemical parameters monitored remain constant at some extent, suggesting a high stability of the raw oil under storage conditions. Special attention is addressed to the evolution of the peroxide index, since it evaluates the level of deterioration of the alkyl chains of the triglycerides. Their values indicate that the raw oil showed no appreciable alterations during the aging period. For freshly extracted oils, values of peroxide index below $10 \mathrm{meq} / \mathrm{kg}$ are considered normal, if one examine that, for higher values, particularly between 20 and $40 \mathrm{meq} / \mathrm{kg}$, characteristic tastes of rancid oil appear [4]. Unlike many 
vegetable oils, the stability of rice oil is caused by its high content of antioxidants present in its as-extracted and asrefined condition [3,38]. These natural antioxidants are unsaponifiable matter of the raw oil. Compounds such as gamma-oryzanol, tocopherols, tocotrienols, squalene, and others have been identified as being responsible for the high oxidative stability of the raw oil, even during heating [2$4,27,37,38]$.

Oxidative stability of oils is commonly evaluated by conductometric method, which uses accelerated oxidation conditions, such as the so-called Rancimat test [39]. This test is based on the conductometric determination of volatile degradation products of the oil. In general, an air flow $(10-20 \mathrm{l} / \mathrm{h})$ is continuously bubbled through the oil which was preheated to $110^{\circ} \mathrm{C}$. The oxygenation of the oil accelerates its degradation and the volatile oxidation products are collected (dissolved) in deionized water, occurring with this an increase in the conductivity of the water. Throughout this process, the variation in the electrical conductivity of water is recorded, and when a strong increase of this conductivity occurs, an induction time is measured. Induction time determines the beginning of the oil degradation, which, in the case of vegetable oils, depends on the heating temperature. At temperatures up to $120^{\circ} \mathrm{C}$, the main reactions are the hydrolysis and oxidation of the oil provoked by moisture and oxygen; at higher temperatures, the polymerization reactions are also important. In general, lipid oxidation is described by a free-radical chain mechanism: the primary oxidation products are hydroperoxide and the secondary oxidation products can be alcohol and carbonyl compounds, such as aldehydes, ketones, and acids $[9,40]$.

Based on the principle of this test and considering that the chemical composition of the deionized water will change during the test due to the dissolution of the volatile oxidation products, besides oxygen from the air, the variation of the OCP of a gold WE was measured. That is, the electric conductivity meter is replaced by a gold working electrode (WE) and a reference electrode (saturated calomel electrode (SCE)). In an equilibrium system, the OCP value of the gold electrode will remain stable; however, when the oxidation products dissolve (in addition to oxygen from the air), changes in OCP of the gold electrode will occur over time. The OCP variation will be related to the kinetics of the redox processes and the concentration of the dissolved species [4143].

In Figure 7 the OCP measurements at different temperatures are shown (air flow of $10 \mathrm{l} / \mathrm{h}$ ). Prior to each test the OCP of the WE into the deionized water was measured during one hour, thereafter the air bubbling into the oil was started, and the outflow stream was bubbled through the deionized water. In general it is observed that the OCP curves showed the presence of two clearly defined slopes. The first one can be associated with the oxygen uptake due to the air bubbling and the second one to the dissolution of the volatile oxidation products.

At $50^{\circ} \mathrm{C}$, once air bubbling started, an increase in OCP values was observed until a steady state was reached. Next, another increase in OCP values was observed until a new steady state was reached. In both cases, the steady state

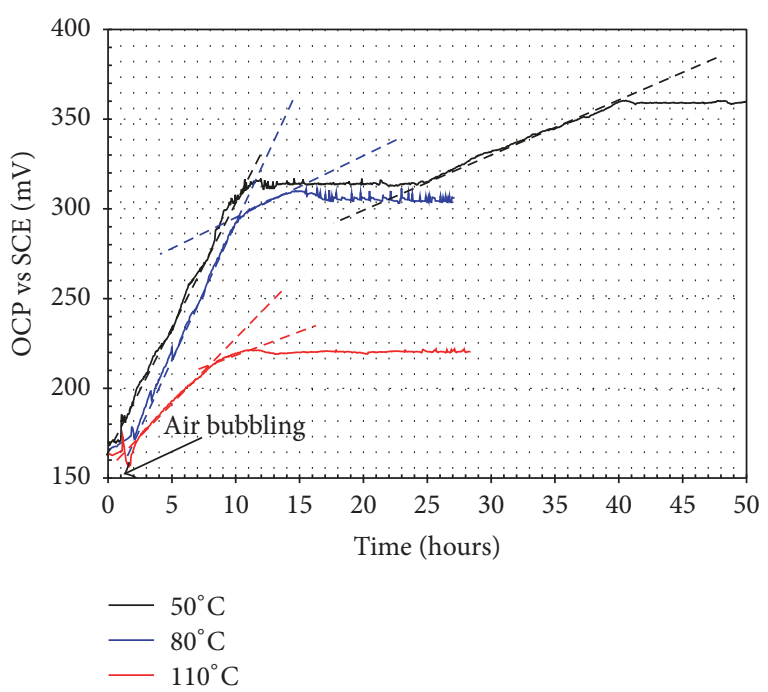

FIGURE 7: OCP measurements during the oxidation of the raw oil at different temperatures.

reached corresponds to the saturation of the solution by the absorbed species, being that the first one corresponds to the maximum absorption of oxygen and the second one to the maximum dissolution of the volatile oxidation products or the completion of the oil oxidation process. At 80 and $110^{\circ} \mathrm{C}$, the second slope occurred without the development of the first steady state observed at $50^{\circ} \mathrm{C}$. This indicates that the dissolution of the volatile oxidation products was the dominant mechanism, before water reached its oxygen saturation. In all cases, the start of the second slope can be considered as the stability time of the raw oil for each test temperature. In this way, it can be said that the oxidative stability of raw oil was 24,9 , and 7 hours at 50,80 , and $110^{\circ} \mathrm{C}$, respectively. Stability values for raw oil at $110^{\circ} \mathrm{C}$ have been reported after 37.24 hours [27] and similarly for raw and refined oil at $120^{\circ} \mathrm{C}$ (after 9.29 and 4.75 hours, respectively) [3] and at $160^{\circ} \mathrm{C}$ ( $\sim .5$ hours) [40]. Variation in these reported results is consequence of many factors that may influence the quality of the oil analyzed, for instance, crop and milling practices and extraction and refining processes, besides the particular conditions of the Rancimat test, such as temperature, partial pressure of oxygen, moisture content of the air stream, and air flow.

Due to the lack of suitable equipment, an evaluation of stability for the raw oil was impossible by the Rancimat test. However, based on the measurement principle of the OPC for an inert material in an electrolyte with variable chemical composition, such measurements are possible and can be a valid alternative to determine the oxidative stability of oils. The natural antioxidants contained in the raw oil increase its shelf life and protect it against the lipoperoxidation induced by heating and exposure to oxygen. The high stability of these oils, rich in mono- and polyunsaturated fatty acids, makes them attractive to be used as unconventional oils for the synthesis of biodiesel. 


\section{Conclusions}

"Morelos rice" bran has high oil content (21.44\%), whose chemical characteristics (48.48\% oleic acid, $35.26 \%$ linoleic acid, and $14.54 \%$ palmitic acid) make it a good candidate to be used both for food and for synthesis of other products with greater added value. However, due to the rapid action of the enzyme lipase, rice bran is susceptible to the degradation of its triglycerides generating a rapid increase in its free fatty acid content even a few hours after the milling process. Morphological aspects of the rice bran particles, influenced by the milling process, favor the rapid extraction of its oil. At least $90 \%$ of its oil content can be recovered in a short time at room temperature. The oil extraction process is carried out by two mechanisms, washing and diffusion, with the former being the main mechanism. The low values of the diffusion coefficient indicate that the recovery of the remaining oil is dependent on the cellular integrity of the rice bran flakes. The aging of the raw oil indicates a high stability under storage conditions which has repercussions on its shelf life. This high stability is due to its high content of antioxidants in its asextracted condition. The proposed technique, based in the open-circuit potential between an inert metal electrode and deionized water, to determine the oxidative stability of oils showed good results, and according to this procedure the oxidative stability of the raw oil was 24,9 , and 7 hours at $50^{\circ} \mathrm{C}$, $80^{\circ} \mathrm{C}$, and $110^{\circ} \mathrm{C}$, respectively.

\section{Conflicts of Interest}

The authors declare that there are no conflicts of interest regarding the publication of this paper.

\section{Acknowledgments}

Financial support from Consejo Nacional de Ciencia y Tecnología (CONACYT, México) (Project 159898) is gratefully acknowledged. J. Zúñiga-Diaz and E. Reyes-Dorantes acknowledge CONACYT (Mexico) for the financial support given to realize their postgraduate studies.

\section{References}

[1] N. El Boulifi, A. Bouaid, M. Martinez, and J. Aracil, "Optimization and oxidative stability of biodiesel production from rice bran oil," Renewable Energy, vol. 53, pp. 141-147, 2013.

[2] K. Gul, B. Yousuf, A. K. Singh, P. Singh, and A. A. Wani, "Rice bran: nutritional values and its emerging potential for development of functional food-a review," Bioactive Carbohydrates and Dietary Fibre, vol. 6, no. 1, pp. 24-30, 2015.

[3] A. G. Gopala Krishna, P. A. Prashanth, A. Pragasam, K. V. Raghavendra, and S. Khatoon, "Unsaponifiable matter and oxidative stability of commercially produced Indian rice bran oils," Journal of Food Lipids, vol. 10, no. 4, pp. 329-340, 2003.

[4] S. Y. Al-Okbi, N. M Ammar, D. A. Mohamed et al., "Egyptian rice bran oil: Chemical analysis of the main phytochemicals," Rivista Italiana Delle Sostanze Grasse, vol. 91, no. 1, pp. 47-58, 2014.
[5] N. R. Lakkakula, M. Lima, and T. Walker, "Rice bran stabilization and rice bran oil extraction using ohmic heating," Bioresource Technology, vol. 92, no. 2, pp. 157-161, 2004.

[6] W. Kong, Q. Kang, W. Feng, and T. Tan, "Improving the solventextraction process of rice bran oil," Chemical Engineering Research and Design, vol. 104, pp. 1-10, 2015.

[7] A. Proctor and D. J. Bowen, "Ambient-temperature extraction of rice bran oil with hexane and isopropanol," Journal of the American Oil Chemists' Society, vol. 73, no. 6, pp. 811-813, 1996.

[8] B. M. W. P. K. Amarasinghe and N. C. Gangodavilage, "Rice bran oil extraction in Sri Lanka data for process equipment design," Food and Bioproducts Processing, vol. 82, no. 1, pp. 5459, 2004.

[9] A. Kamal-Eldin, "Effect of fatty acids and tocopherols on the oxidative stability of vegetable oils," European Journal of Lipid Science and Technology, vol. 108, no. 12, pp. 1051-1061, 2006.

[10] J. M. Tolentino-Martínez, "The rice production of the state of Morelos under the approach SIAL," Estudios Sociales (Hermosillo, Son.), vol. 22, no. 44, pp. 39-61, 2014.

[11] E. R. Baümler, M. E. Carrín, and A. A. Carelli, "Extraction of sunflower oil using ethanol as solvent," Journal of Food Engineering, 2015.

[12] L. A. Rigo, A. R. Pohlmann, S. S. Guterres, and R. C. R. Beck, "Rice bran oil: benefits to health and applications in pharmaceutical formulations," in Wheat and Rice in Disease Prevention and Health: Benefits, Risks and Mechanisms of Whole Grains in Health Promotion, R. R. Watson, V. Preedy, and S. Zibadi, Eds., pp. 311-322, Academic Press, 2014, http://doi.org/10.1016/B9780-12-401716-0.00023-4.

[13] S. Sayasoonthorn, S. Kaewrueng, and P. Patharasathapornkul, "Rice Bran Oil Extraction by Screw Press Method: Optimum Operating Settings, Oil Extraction Level and Press Cake Appearance," Rice Science, vol. 19, no. 1, pp. 75-78, 2012.

[14] A. Srivastava and R. Prasad, "Triglycerides-based diesel fuels," Renewable and Sustainable Energy Reviews, vol. 4, no. 2, pp. 111133, 2000.

[15] C. Borchani, S. Besbes, C. Blecker, and H. Attia, "Chemical characteristics and oxidative stability of sesame seed, sesame paste, and olive oils," Journal of Agricultural Science and Technology, vol. 12, pp. 585-596, 2010.

[16] G. Toscano, G. Riva, E. Foppa Pedretti, and D. Duca, "Vegetable oil and fat viscosity forecast models based on iodine number and saponification number," Biomass and Bioenergy, vol. 46, pp. 511-516, 2012.

[17] J. Yi-Hsu and S. R. Vali, "Rice bran oil as a potential resource for biodiesel: a review," Journal of Scientific and Industrial Research, vol. 64, pp. 866-882, 2005.

[18] L. Lin, D. Ying, S. Chaitep, and S. Vittayapadung, "Biodiesel production from crude rice bran oil and properties as fuel," Applied Energy, vol. 86, no. 5, pp. 681-688, 2009.

[19] J. Van Gerpen, "Biodiesel processing and production," Fuel Processing Technology, vol. 86, no. 10, pp. 1097-1107, 2005.

[20] E. Akbar, Z. Yaakob, S. K. Kamarudin, M. Ismail, and J. Salimon, "Characteristic and composition of jatropha curcas oil seed from Malaysia and its potential as biodiesel feedstock feedstock," European Journal of Scientific Research, vol. 29, no. 3, pp. 396-403, 2009.

[21] J. Porcayo-Calderon, L. M. Martínez de la Escalera, J. Canto, and M. Casales-Diaz, "Imidazoline Derivatives based on coffee oil as $\mathrm{CO}_{2}$ corrosion inhibitor," International Journal of Electrochemical Science, vol. 10, no. 4, pp. 3160-3176, 2015. 
[22] J. Porcayo-Calderon, I. Regla, E. Vazquez-Velez et al., "Effect of the unsaturation of the hydrocarbon chain of fatty-amides on the $\mathrm{CO}_{2}$-corrosion of carbon steel using EIS and real-time corrosion measurement," Journal of Spectroscopy, vol. 2015, Article ID 184140, 10 pages, 2015.

[23] M. Lopez, J. Porcayo-Calderon, M. Casales-Diaz, I. Carrillo, J. Canto, L. M. Martinez de la Escalera et al., "Internal corrosion solution for gathering production gas pipelines involving palm oil amide based corrosion inhibitors," International Journal of Electrochemical Science, vol. 10, no. 9, pp. 7166-7179, 2015.

[24] S. Godavarthi, J. Porcayo-Calderon, M. Casales-Diaz, E. Vazquez-Velez, A. Neri, and L. Martinez-Gomez, "Electrochemical analysis and quantum chemistry of castor oil-based corrosion inhibitors," Current Analytical Chemistry, vol. 12, no. 5, pp. 476-488, 2016.

[25] J. M. Encinar, J. F. González, and A. Rodríguez-Reinares, "Biodiesel from used frying oil. Variables affecting the yields and characteristics of the biodiesel," Industrial \& Engineering Chemistry Research, vol. 44, no. 15, pp. 5491-5499, 2005.

[26] O. E. Ikwuagwu, I. C. Ononogbu, and O. U. Njoku, "Production of biodiesel using rubber [Hevea brasiliensis (Kunth. Muell.)] seed oil," Industrial Crops and Products, vol. 12, no. 1, pp. 57-62, 2000.

[27] E. L. Bakota, J. K. Winkler-Moser, H.-S. Hwang, M. J. Bowman, D. E. Palmquist, and S. X. Liu, "Solvent fractionation of rice bran oil to produce a spreadable rice bran product," European Journal of Lipid Science and Technology, vol. 115, no. 8, pp. 847-857, 2013.

[28] M. J. Lerma-García, G. Ramis-Ramos, J. M. Herrero-Martínez, and E. F. Simó-Alfonso, "Authentication of extra virgin olive oils by Fourier-transform infrared spectroscopy," Food Chemistry, vol. 118, no. 1, pp. 78-83, 2010.

[29] M. D. Guillen and N. Cabo, "Characterization of edible oils and lard by Fourier transform infrared spectroscopy. Relationships between composition and frequency of concrete bands in the fingerprint region," Journal of the American Oil Chemists' Society, vol. 74, no. 10, pp. 1281-1286, 1997.

[30] Sh. K. Amin and H. A. M. Abdallah, "Enhancement of free fatty acid in rice bran oil for acid catalysis biodiesel production," Australian Journal of Basic and Applied Sciences, vol. 6, no. 3, pp. 795-806, 2012.

[31] T. H. Varzakas, G. C. Leach, C. J. Israilides, and D. Arapoglou, "Theoretical and experimental approaches towards the determination of solute effective diffusivities in foods," Enzyme and Microbial Technology, vol. 37, no. 1, pp. 29-41, 2005.

[32] M. E. Carrín and G. H. Crapiste, "Mathematical modeling of vegetable oil-solvent extraction in a multistage horizontal extractor," Journal of Food Engineering, vol. 85, no. 3, pp. 418425, 2008.

[33] J. I. Crossley and J. M. Aguilera, "Modeling the effect of microstructure on food extraction," Journal of Food Process Engineering, vol. 24, no. 3, pp. 161-177, 2001.

[34] I. Doymaz, "Convective air drying characteristics of thin layer carrots," Journal of Food Engineering, vol. 61, no. 3, pp. 359-364, 2004.

[35] S. J. Babalis and V. G. Belessiotis, "Influence of the drying conditions on the drying constants and moisture diffusivity during the thin-layer drying of figs," Journal of Food Engineering, vol. 65, no. 3, pp. 449-458, 2004.

[36] E. R. Baümler, G. H. Crapiste, and A. A. Carelli, "Solvent extraction: Kinetic study of major and minor compounds," JAOCS, Journal of the American Oil Chemists' Society, vol. 87, no. 12, pp. 1489-1495, 2010.
[37] C. Juliano, M. Cossu, M. C. Alamanni, and L. Piu, "Antioxidant activity of gamma-oryzanol: mechanism of action and its effect on oxidative stability of pharmaceutical oils," International Journal of Pharmaceutics, vol. 299, no. 1-2, pp. 146-154, 2005.

[38] A. G. G. Krishna, S. Khatoon, P. M. Shiela, C. V. Sarmandal, T. N. Indira, and A. Mishra, "Effect of refining of crude rice bran oil on the retention of oryzanol in the refined oil," Journal of the American Oil Chemists' Society, vol. 78, no. 2, pp. 127-131, 2001.

[39] Official Methods and Recommended Practices of the AOCS, American Oil Chemists Society, Champaign, USA, 1983.

[40] F. B. Gonzaga and C. Pasquini, "A new method for determination of the oxidative stability of edible oils at frying temperatures using near infrared emission spectroscopy," Analytica Chimica Acta, vol. 570, no. 1, pp. 129-135, 2006.

[41] J. H. Park, H. Zhou, S. J. Percival, B. Zhang, F.-R. F. Fan, and A. J. Bard, "Open circuit (mixed) potential changes upon contact between different inert electrodes-size and kinetic effects," Analytical Chemistry, vol. 85, no. 2, pp. 964-970, 2013.

[42] G. Horanyi, G. Inzelt, and E. Szetey, "pen circuit potential oscillations of platinum electrodes immersed in solutions of organic fuels and redox systems. Imitation of galvanostatic potentialoscillations observed in the course of electrooxidation of organic fuels," Journal of Electroanalytical Chemistry and Interfacial Electrochemistry, vol. 81, no. 2, pp. 395-401, 1977.

[43] S. Szabó and I. Bakos, "Reference electrodes in metal corrosion," International Journal of Corrosion, vol. 2010, Article ID 756950, 2010. 

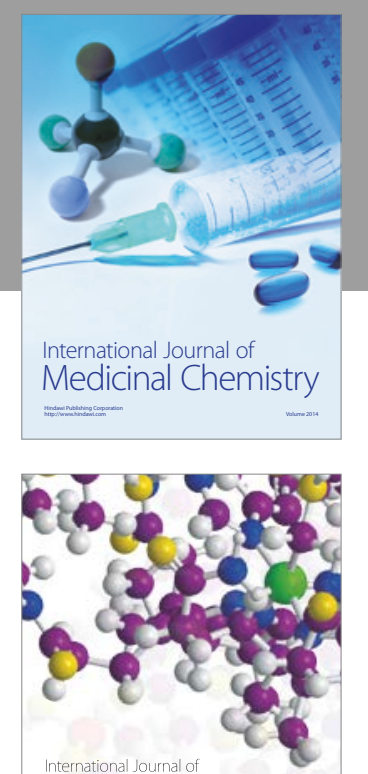

Carbohydrate Chemistry

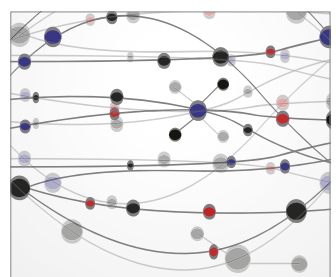

The Scientific World Journal
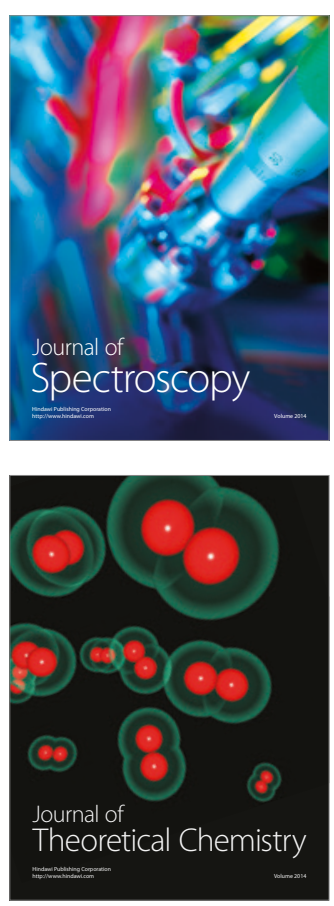
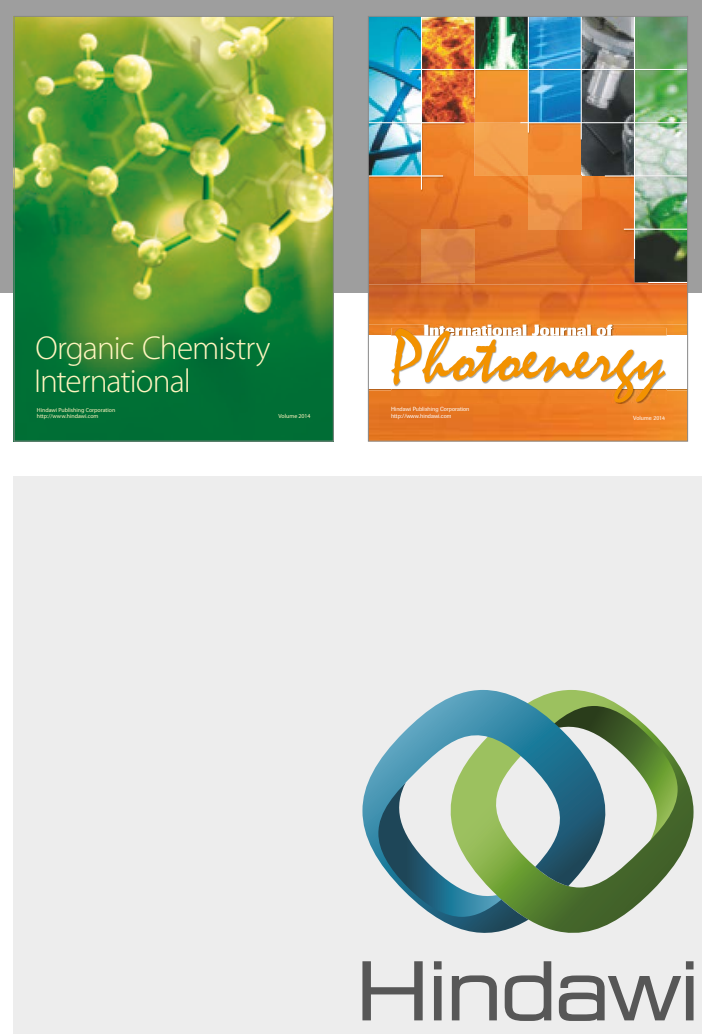

Submit your manuscripts at

https://www.hindawi.com

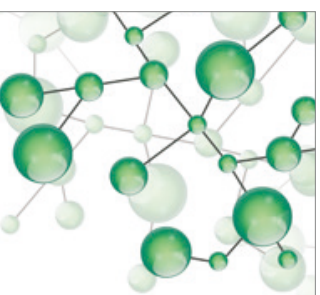

International Journal of

Inorganic Chemistry

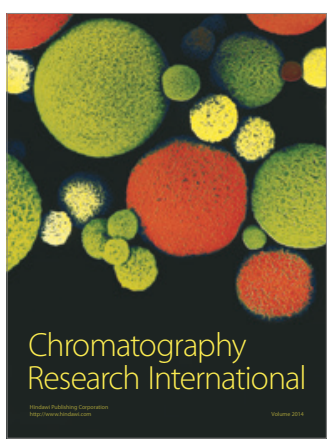

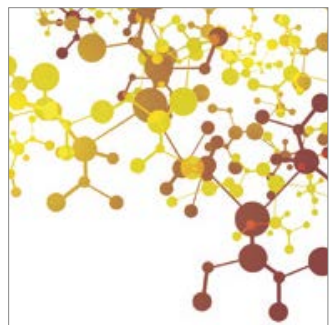

Applied Chemistry
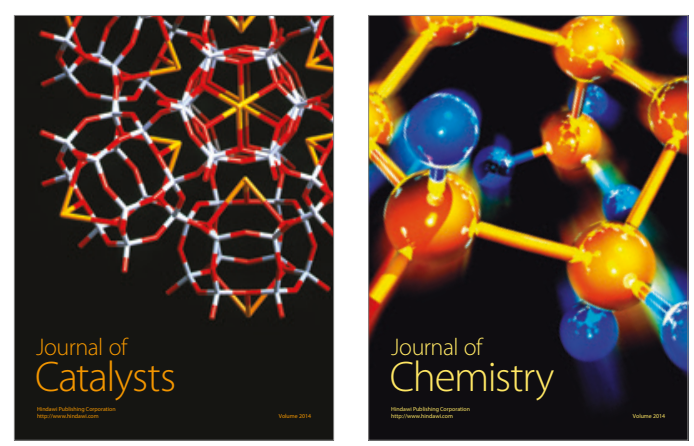
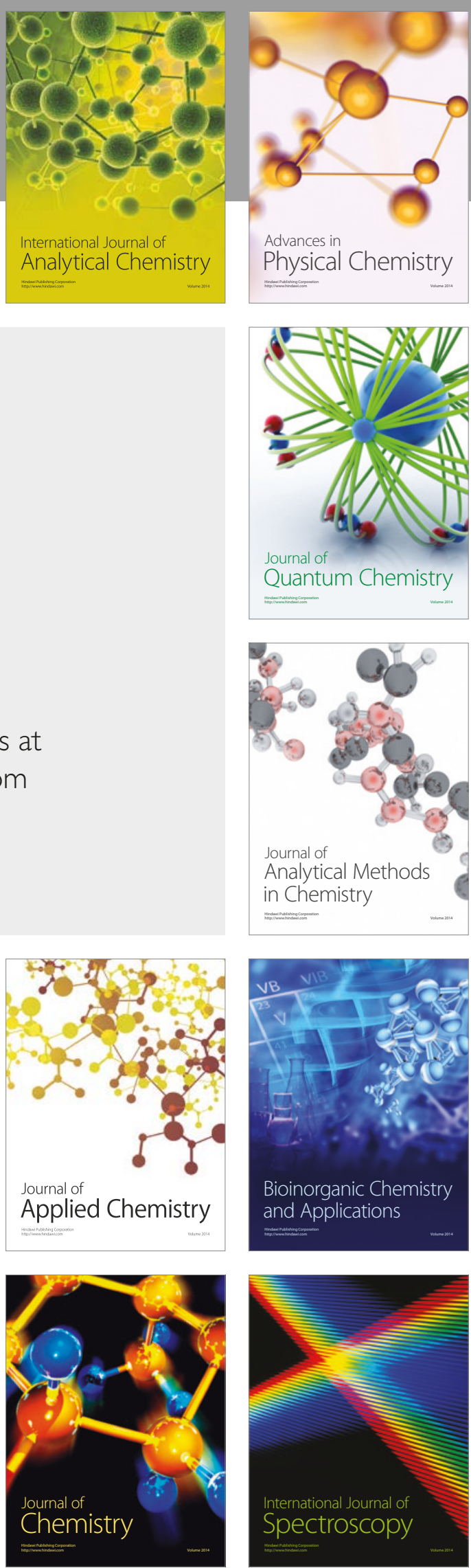